Article

\title{
The Influence of Processing Parameters on the Mitigation of Deoxynivalenol during Industrial Baking
}

\author{
David Stadler ${ }^{1}$, Francesca Lambertini ${ }^{2}$, Lydia Woelflingseder ${ }^{3}$, Heidi Schwartz-Zimmermann ${ }^{1}$, \\ Doris Marko $^{3}$, Michele Suman ${ }^{2} \mathbb{D}$, Franz Berthiller ${ }^{1, *(\mathbb{C})}$ and Rudolf Krska ${ }^{1,4} \mathbb{( B}$ \\ 1 Institute of Bioanalytics and Agro-Metabolomics, Department of Agrobiotechnology (IFA-Tulln), University \\ of Natural Resources and Life Sciences, Vienna (BOKU), Konrad-Lorenz-Str. 20, 3430 Tulln, Austria; \\ david.stadler@boku.ac.at (D.S.); heidi.schwartz@boku.ac.at (H.S.-Z.); rudolf.krska@boku.ac.at or \\ r.krska@qub.ac.uk (R.K.) \\ 2 Barilla G. R. F.lli SpA, Advanced Laboratory Research, via Mantova 166, 43122 Parma, Italy; \\ francesca.lambertini@barilla.com (F.L.); michele.suman@barilla.com (M.S.) \\ 3 Department of Food Chemistry and Toxicology, University of Vienna, Währingerstraße 38, 1090 Vienna, \\ Austria; lydia.woelflingseder@univie.ac.at (L.W.); doris.marko@univie.ac.at (D.M.) \\ 4 Institute for Global Food Security, School of Biological Sciences, Queens University Belfast, University Road, \\ Belfast BT7 1NN, Northern Ireland, UK \\ * Correspondence: franz.berthiller@boku.ac.at; Tel.: +43-1-47654-97371
}

Received: 13 May 2019; Accepted: 30 May 2019; Published: 4 June 2019

\begin{abstract}
Deoxynivalenol (DON), a frequent contaminant of flour, can be partially degraded by baking. It is not clear: (i) How the choice of processing parameter (i.e., ingredients, leavening, and baking conditions) affects DON degradation and thus (ii) how much DON can be degraded during the large-scale industrial production of bakery products. Crackers, biscuits, and bread were produced from naturally contaminated flour using different processing conditions. DON degradation during baking was quantified with the most accurate analytical methodology available for this Fusarium toxin, which is based on liquid chromatography tandem mass spectrometry. Depending on the processing conditions, $0-21 \%, 4-16 \%$, and $2-5 \%$ DON were degraded during the production of crackers, biscuits, and bread, respectively. A higher $\mathrm{NaHCO}_{3}$ concentration, baking time, and baking temperature caused higher $\mathrm{DON}$ degradation. $\mathrm{NH}_{4} \mathrm{HCO}_{3}$, yeast, vinegar, and sucrose concentration as well as leavening time did not enhance DON degradation. In vitro cell viability assays confirmed that the major degradation product isoDON is considerably less toxic than DON. This proves for the first time that large-scale industrial baking results in partial detoxification of DON, which can be enhanced by process management.
\end{abstract}

Keywords: mycotoxins; trichothecenes; thermal degradation; decontamination; mass spectrometry; food processing; detoxification; design of experiment; LC-MS/MS

Key Contribution: Deoxynivalenol (DON) can be partially detoxified during the industrial production of bakery products. The detoxification of DON can be enhanced by process management.

\section{Introduction}

Deoxynivalenol (DON) is along with aflatoxins, fumonisins, ochratoxin $\mathrm{A}$, and zearalenone, one of the main mycotoxins of significance for human disease [1]. DON frequently contaminates cereals and cereal-based products [2]. The population of the European Union (EU) is frequently exposed to DON mainly due to the consumption of bread and other bakery wares [2]. Therefore, the European 
Commission (EC) has set maximum levels for DON in milling products and bread/bakery wares of $750 \mu \mathrm{g} / \mathrm{kg}$ and $500 \mu \mathrm{g} / \mathrm{kg}$, respectively [3]. This legislation follows the rationale that it is feasible to reduce DON from flour during the production of bakery products by $33 \%$. This assumption is supported by the recent report on the risk associated with DON in food by the European Food Safety Authority (EFSA) [2]. From 2007 to 2014, EFSA gathered occurrence data for the concentration of DON present in different food groups. For milling products, bread and rolls, and fine bakery wares, 4609, 2837 , and 975 data points, respectively, were collected from the EU member states. The mean and 95th percentile concentrations of DON were 20-30\% lower in bread and bakery wares (bread and rolls, fine bakery wares) than in flour (milling products).

During baking, DON was found to degrade mainly to isoDON, but also to norDON B and norDON $C$ [4-6]. norDON B and norDON C were found to be considerably less cytotoxic than DON [5]. isoDON was found to have much lower inhibitory potency on the ribosome than DON, which is strongly indicative of its overall lower toxicity [6].

The reduction of the DON concentration during baking can be due to formulation (i.e., the dilution effect due to mixing contaminated flour with non-contaminated ingredients) or due to degradation of DON. The reduction due to formulation can be easily calculated from the percentage of flour of the finished bakery product, assuming no additional sources of DON. The extent of the DON degradation during baking, however, was reported to be very variable $[2,7,8]$. This high variation can be explained by errors in the calculation of the amount of DON that was degraded (e.g., by not considering the dilution with other ingredients) and by not performing baking trials with a suitable number of replicates. Recently, we identified all degradation products of DON, formed during baking of crackers, biscuits, and bread, using a stable isotope labelling approach combined with high resolution mass spectrometry analysis. After quantifying DON and all of its formed degradation products, we were able to provide the first comprehensive mass balance for those commodities [6].

In this current study, DON degradation during the production of crackers, biscuits, and bread from flour fortified with DON was determined to be $6 \%, 5 \%$, and $2 \%$, respectively, based on the increase of degradation products. As this study was aimed at the elucidation of the degradation products that are formed during baking, the experiments were carried out under standard baking conditions. As a step forward, the influence of the processing conditions should be evaluated. Furthermore, experiments with naturally contaminated flour need to be conducted in order to reproduce the actual industrial starting conditions in place during the large-scale production of bakery products.

The influence of different processing parameters on DON degradation during the production of crackers, biscuits, bread, and rusks was determined in previous studies [9-12]. Statistical evaluation of the DON concentration showed that baking temperature, baking time, and the concentration of the raising agent $\mathrm{NaHCO}_{3}$ influence the amount of DON in the final products. However, the statistical models as well as the determination of the DON degradation may have suffered from the high analytical variability of the determination of the DON concentration.

We hypothesized that DON degradation during industrial baking is influenced by the choice of processing parameter (i.e., ingredients, leavening, and baking conditions). Hence, the objectives of this study were to: (i) Produce bakery products (crackers, biscuits, and bread) from naturally contaminated flour using different processing conditions, (ii) determine DON degradation by LC-MS/MS based quantification of the DON degradation products and iii) develop a statistical model which shows the influence of the processing parameters on the DON degradation. Due to the comprehensive baking trials in combination with the highly sensitive LC-MS/MS analysis and the consideration of all formed degradation products, this study presents the most accurate report on the effect of industrial baking on DON degradation to date. Moreover, a first characterization of the cytotoxicity of isoDON, compared to $\mathrm{DON}$, is presented. 


\section{Results}

To study the main processing factors affecting the mitigation of DON during industrial baking, crackers, biscuits, and bread were chosen as representative commodities of the main bakery categories produced with very different technologies. A Design of Experiments (DoE) approach was applied to set up the experimental trials. In agreement with results previously obtained by our research group [9,10,12], the main technological parameters monitored were: (i) Baking conditions (i.e., time and temperature), (ii) $\mathrm{pH}$ modifying agents $\left(\mathrm{NaHCO}_{3}, \mathrm{NH}_{4} \mathrm{HCO}_{3}\right.$, and other minor ingredients) and (iii) leavening conditions (time, temperature, presence, and type of leavening agents). Each factor was modified within a range according to technological feasibility. Some conditions stressed the process over the organoleptic acceptability of the final product. These processing conditions were chosen to promote significant changes of the DON concentration in order to understand the impact of the applied processing conditions. In the present work, all the food commodities were produced at a pilot plant level. As a starting point of the DoE approach, the same processing parameters as those on common industrial processing lines were chosen. Figure 1 exemplifies the influence of the baking conditions on the final appearance of biscuits, bread and crackers.

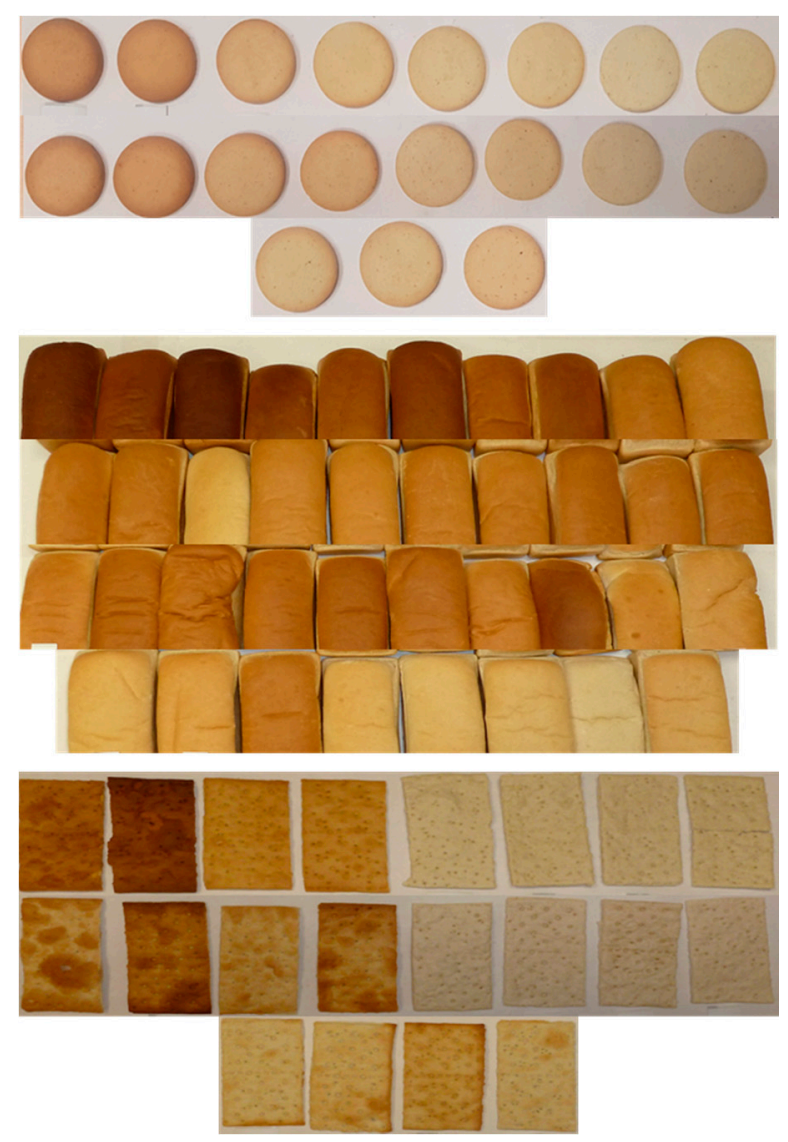

Figure 1. Display of the influence of baking conditions on the appearance of biscuits (top), bread (middle) and crackers (bottom).

\subsection{Incluence of Processing Parameters on DON Degradation during the Production of Bakery Products}

For all three baking commodities, the results of the experimental trials were evaluated and presented in two sub-chapters. First, the sum of the DON degradation products, which is the measure for DON degradation, was shown as a bar graph. The individual experiments were listed according to the processing parameters that were found to be important for DON degradation based on a visual assessment. In this way, Figures 2, 4, and 6 show the DON degradation that was achieved under 
the specified processing conditions ranked from high to low DON degradation. These bar graphs give a first impression of the DON degradation and the influence of the processing parameter for the individual commodities. Second, to confirm and refine the conclusions of the visual assessment, a DoE model was built using the MODDE software tool. The outcome of this statistical analysis is visualized by an effects plot which displays the change of the sum of the DON degradation products when a processing factor is varied from its lowest to its highest value (Figures 3, 5, and 7, top). The data set obtained from the DoE model was used to build a prediction model for the influence of the process parameter that led to a statistically significant increase of DON degradation. These predictive factor plots show how DON degradation can be enhanced by the design of the production process (Figures 3, 5, and 9, bottom). To allow for the easy comparability of the results between the three baking commodities, the same scaling was chosen for the individual graphs.

\subsubsection{Biscuits}

Biscuits, from the technological point of view, represent a quite simple bakery preparation characterized by a baking step and the use of raising agents. In order to monitor the impact of these two factors on the DON content in the final products, a very basic recipe was chosen, containing only flour, oil, sugar, and water, with the addition of $\mathrm{NaHCO}_{3}$ and $\mathrm{NH}_{4} \mathrm{HCO}_{3}$ as leavening agents. Several batches of biscuits were prepared at different conditions according to the DoE inputs based on the Screening Interaction model. In the present study, the processing parameters $\mathrm{NaHCO}_{3}$ concentration, $\mathrm{NH}_{4} \mathrm{HCO}_{3}$ concentration, baking time, baking temperature, and sugar content were varied (Table $\mathrm{S} 1$ ). Due to the different production conditions, DON degradation varied between 4-16\% (Figure 2).
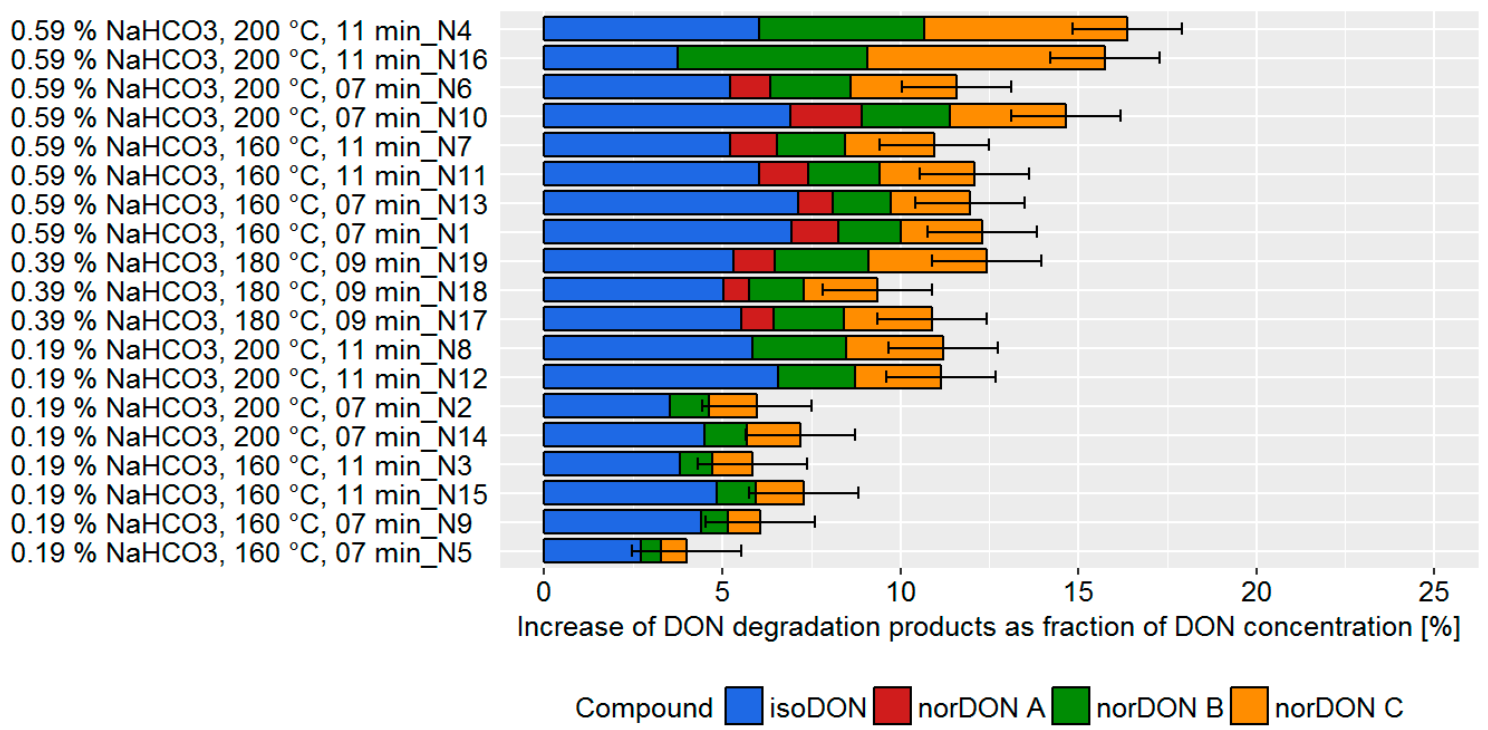

Figure 2. Increase of the deoxynivalenol (DON) degradation products isoDON and norDONs A-C during the production of biscuits using different processing conditions. The increase was determined as a ratio of the molal concentration of the DON degradation products to the molal concentration of DON resulting from the natural contamination of the flour. The experimental trials were listed according to the $\mathrm{NaHCO}_{3}$ concentration, baking temperature, and baking time. Error bars represent the process standard deviation.

A higher DON degradation was observed in batches with a higher concentration of $\mathrm{NaHCO}_{3}$, baking temperature, and baking time. The variation of the processing parameter also led to a changed ratio of the degradation products with the main degradation products being norDON B and C, instead of isoDON, for experiments with a higher baking temperature and baking time. norDON A, which was not found to be a degradation product in our previous study [6], was found only at processing conditions that lead to higher DON degradation. 
The DoE model confirmed that the main factors affecting DON degradation were: (i) The quantity of $\mathrm{NaHCO}_{3}$ used, (ii) the baking temperature, and (iii) the baking time (Figure 3, top). In addition, the statistical model indicates that a synergistic effect of baking temperature and time exists. Changes in $\mathrm{NH}_{4} \mathrm{HCO}_{3}$ and sucrose concentration did not significantly influence DON degradation products. The prediction model for the influence of the processing parameter on DON degradation revealed that by increasing the $\mathrm{NaHCO}_{3}$ concentration from 0.2 to $0.6 \%$, DON degradation is increased by $5 \%$ (Figure 3, bottom). An increase in baking temperature and time is predicted to enhance DON degradation by about $2 \%$.
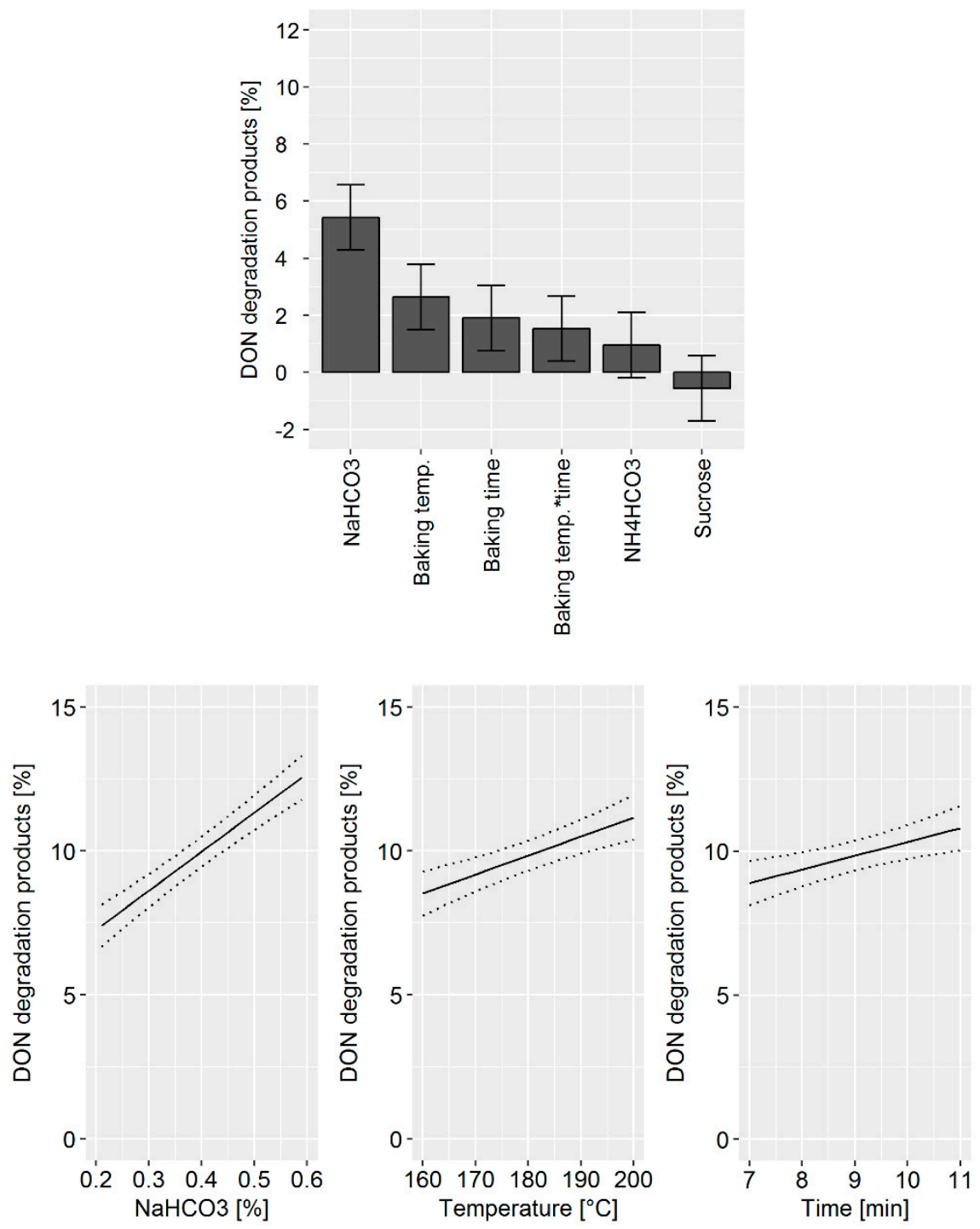

Figure 3. Top: Effects plot, which shows the change of the sum of the DON degradation products when a processing factor is varied from its lowest to its highest value and all other factors are kept at their averages, which was obtained for the design of the experiment (DoE) data set in pilot-scale biscuit making experiments. Error bars represent the confidence interval corresponding to a $95 \%$ confidence level. "** between two processing factors indicates a synergistic effect, which cannot be explained solely by addition of degradation caused by the two parameters individually. Bottom: Predictive factor effect plots, which show the influence of the following processing parameters on the deoxynivalenol (DON) degradation during the biscuit production: (i) $\mathrm{NaHCO}_{3}$ (left), (ii) baking temperature (middle), and (iii) baking time (right). The dotted lines represent the confidence interval corresponding to a $95 \%$ confidence level. 


\subsubsection{Bread}

Bread is surely the most representative and most studied commodity of soft bakery products. Its production workflow implies dough fermentation before baking. Both fermentation and subsequent baking can be managed for time and temperature. The fermentation phase can also be modulated for relative humidity conditions, yeast, bakery improvers, raising agents, and $\mathrm{pH}$. As a consequence, the number of factors to investigate for assessing potential DON mitigation effects was quite high. Therefore, in comparison to biscuits and crackers, more pilot plant trials had to be carried out. Based on literature data and our experience, the following variables were taken into account for the DoE approach: Baking temperature, baking time, leavening time, yeast, sucrose, and cider vinegar concentration. Each factor was varied within a range defined according to technological feasibility (Table S4). Depending on the processing parameter, DON degradation varied from 2-5\% (Figure 4).

$29 \min , 225^{\circ} \mathrm{C}, 1.41 \%$ sucr._N32

$29 \min , 225{ }^{\circ} \mathrm{C}, 1.41 \%$ sucr._N28

$29 \min , 225^{\circ} \mathrm{C}, 1.41 \%$ sucr._N24

$29 \min , 225{ }^{\circ} \mathrm{C}, 1.41 \%$ sucr._N20

$29 \min , 225^{\circ} \mathrm{C}, 0.41 \%$ sucr._N8

$29 \min , 225^{\circ} \mathrm{C}, 0.41 \%$ sucr._N4

$29 \min , 225^{\circ} \mathrm{C}, 0.41 \%$ sucr._N16

$29 \min , 225^{\circ} \mathrm{C}, 0.41 \%$ sucr._N12

$29 \min , 185^{\circ} \mathrm{C}, 1.41 \%$ sucr._N36

$29 \mathrm{~min}, 185^{\circ} \mathrm{C}, 1.41 \%$ sucr._N31

$29 \min , 185{ }^{\circ} \mathrm{C}, 1.41 \%$ sucr._N27

$29 \min , 185^{\circ} \mathrm{C}, 1.41 \%$ sucr._N23

$29 \min , 185^{\circ} \mathrm{C}, 1.41 \%$ sucr. N19

$29 \mathrm{~min}, 185^{\circ} \mathrm{C}, 0.41 \%$ sucr._N7

$29 \min , 185^{\circ} \mathrm{C}, 0.41 \%$ sucr._N3

$29 \mathrm{~min}, 185^{\circ} \mathrm{C}, 0.41 \%$ sucr._N15

$29 \min , 185^{\circ} \mathrm{C}, 0.41 \%$ sucr. N11

$22 \mathrm{~min}, 205^{\circ} \mathrm{C}, 0.91 \%$ sucr._N38

$22 \min , 205^{\circ} \mathrm{C}, 0.91 \%$ sucr._N35

$22 \mathrm{~min}, 205{ }^{\circ} \mathrm{C}, 0.91 \%$ sucr._N34

$22 \min , 205^{\circ} \mathrm{C}, 0.91 \%$ sucr. N33

$15 \mathrm{~min}, 225^{\circ} \mathrm{C}, 1.41 \%$ sucr._N30

$15 \mathrm{~min}, 225^{\circ} \mathrm{C}, 1.41 \%$ sucr._N26

$15 \mathrm{~min}, 225^{\circ} \mathrm{C}, 1.41 \%$ sucr._N22

$15 \mathrm{~min}, 225^{\circ} \mathrm{C}, 1.41 \%$ sucr._N18

$15 \min , 225^{\circ} \mathrm{C}, 0.41 \%$ sucr._N6

$15 \min , 225^{\circ} \mathrm{C}, 0.41 \%$ sucr._N2

$15 \mathrm{~min}, 225^{\circ} \mathrm{C}, 0.41 \%$ sucr._N14

$15 \min , 225^{\circ} \mathrm{C}, 0.41 \%$ sucr._N10

$15 \mathrm{~min}, 185^{\circ} \mathrm{C}, 1.41 \%$ sucr._N37

$15 \mathrm{~min}, 185{ }^{\circ} \mathrm{C}, 1.41 \%$ sucr._N29

$15 \mathrm{~min}, 185^{\circ} \mathrm{C}, 1.41 \%$ sucr._N25

$15 \mathrm{~min}, 185^{\circ} \mathrm{C}, 1.41 \%$ sucr. $\mathrm{N} 21$

$15 \mathrm{~min}, 185^{\circ} \mathrm{C}, 1.41 \%$ sucr._N17

$15 \min , 185^{\circ} \mathrm{C}, 0.41 \%$ sucr._N9

$15 \mathrm{~min}, 185^{\circ} \mathrm{C}, 0.41 \%$ sucr._N5

$15 \mathrm{~min}, 185{ }^{\circ} \mathrm{C}, 0.41 \%$ sucr._N13

$15 \mathrm{~min}, 185^{\circ} \mathrm{C}, 0.41 \%$ sucr._N1

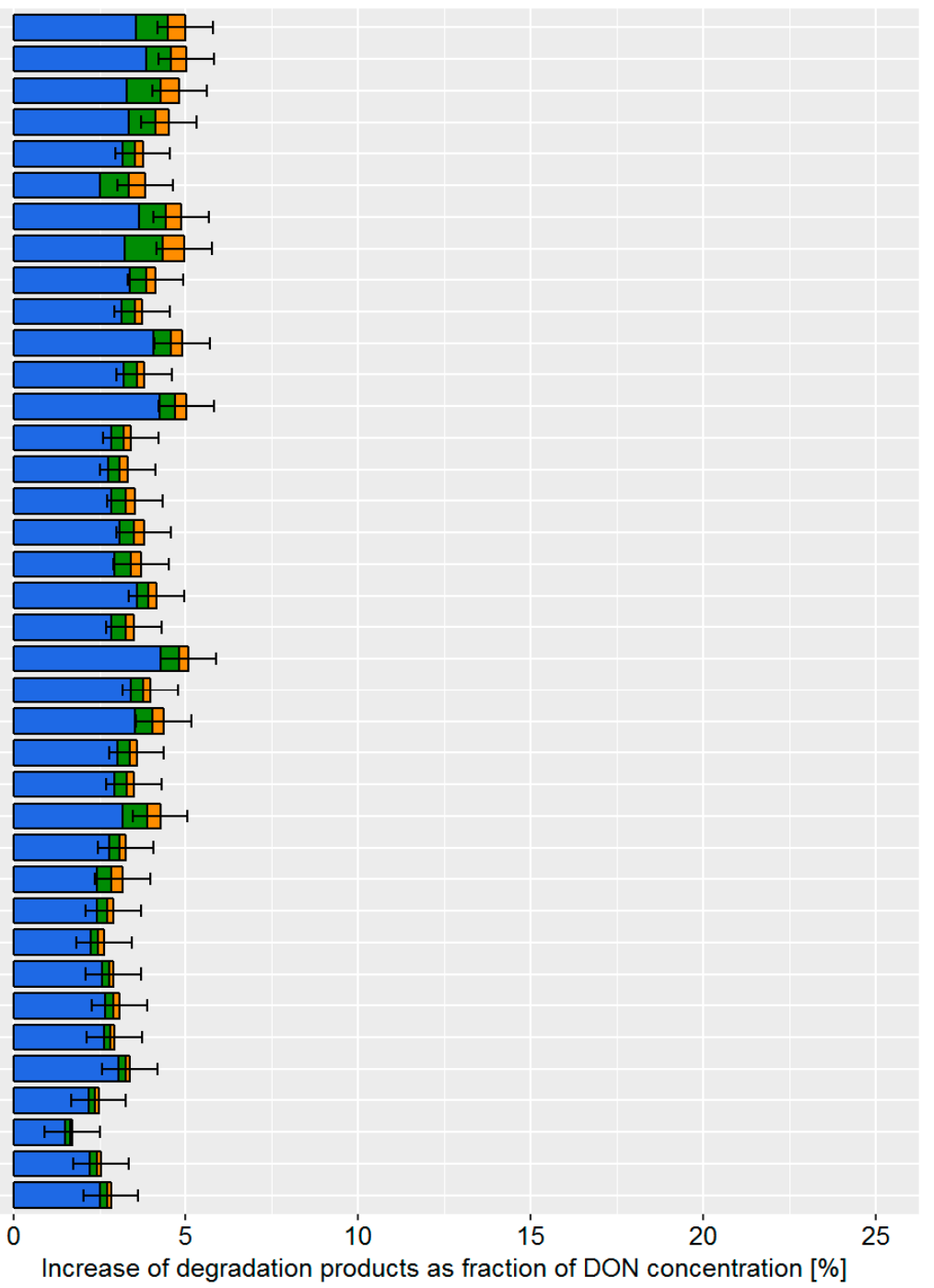

Compound isoDON norDON B norDON C

Figure 4. Increase of the deoxynivalenol (DON) degradation products isoDON and norDONs B-C during the production of bread using different processing conditions. The increase was determined as a ratio of the molal concentration of the DON degradation products to the molal concentration of DON resulting from the natural contamination of the flour. The experimental trials were listed according to baking temperature, baking time, and sucrose concentration. Error bars represent the process standard deviation. 
During the bread production, the achievable DON degradation was found to be low compared to the biscuit and cracker production. Although the influence was small, we found that the baking time and temperature as well as the sucrose concentration impacted the DON concentrations. The DoE model confirmed that the main factors influencing DON degradation were: (i) Baking time, (ii) baking temperature, and (iii) sucrose concentration (Figure 5, top). Changes in cider vinegar and yeast concentration as well as the leavening time did not influence DON degradation. The prediction model confirmed that changes in the processing parameter have only a minor effect of approximately $2 \%$ on DON degradation (Figure 5, bottom).
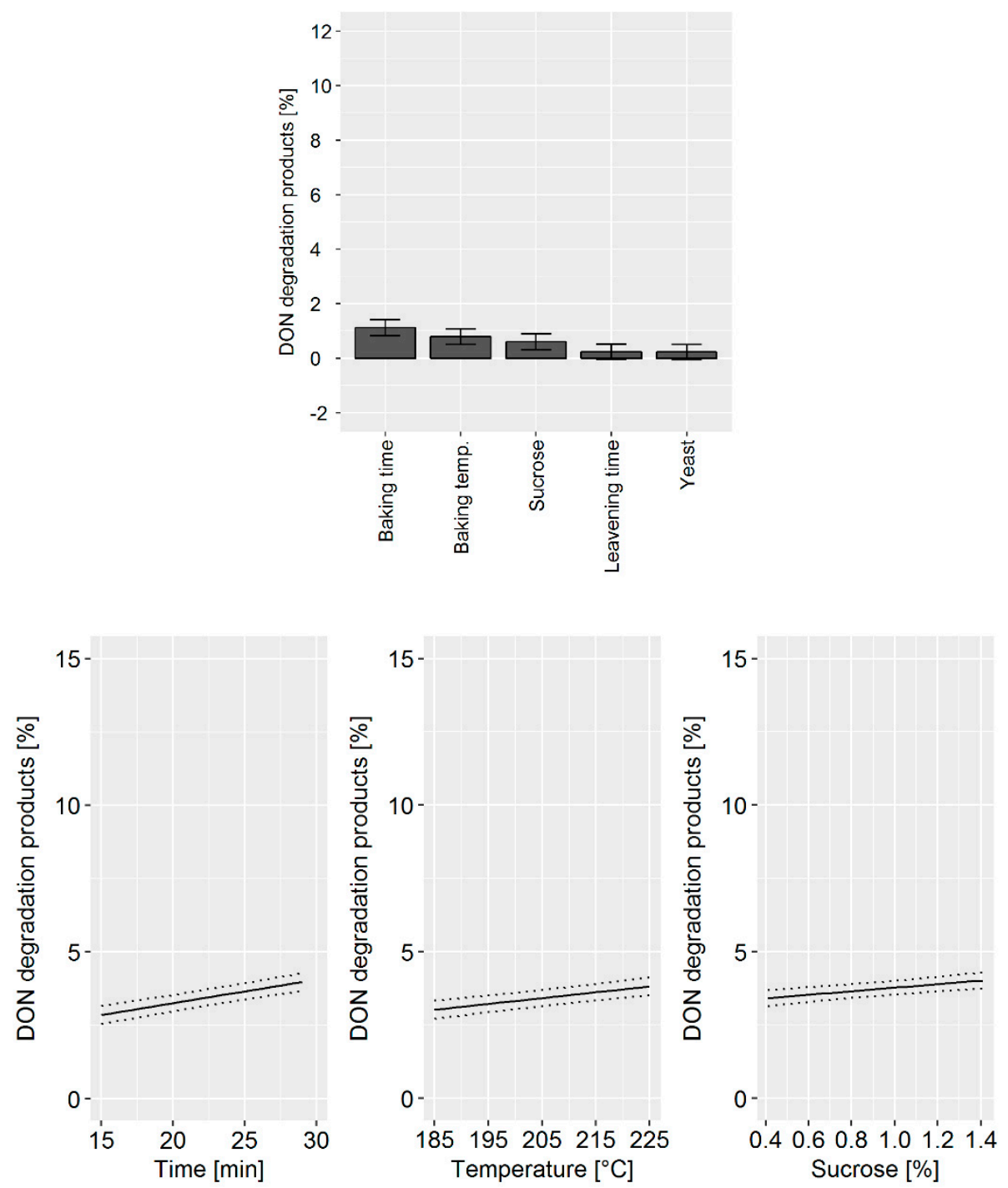

Figure 5. Top: Effects plot, which shows the change of the sum of the DON degradation products when a processing factor is varied from its lowest to its highest value and all other factors are kept at their averages, which was obtained for the design of the experiment (DoE) data set in pilot-scale bread making experiments. Error bars represent the confidence interval corresponding to a $95 \%$ confidence level. Bottom: Predictive factor effect plots, which show the influence of the following processing parameters on the deoxynivalenol (DON) degradation during the biscuit production: (i) Baking time (left), (ii) baking temperature (middle), and (iii) sucrose concentration (right). The dotted lines represent the confidence interval corresponding to a $95 \%$ confidence level. 


\subsubsection{Crackers}

Crackers were chosen as being representative of a complex baking commodity involving different technological aspects and combining several factors which were demonstrated to affect DON mitigation in the previous experiments carried out on biscuits and bread. Among the cracker making parameters, the following conditions were considered as factors in the experimental design: Baking time, baking temperature, acidic mother content, and $\mathrm{NaHCO}_{3}$ concentration. For this trial, each factor was varied within a range defined according to technological feasibility (Table S7). During the cracker production, the DON degradation varied from $0-21 \%$, depending on the choice of processing parameters (Figure 6).
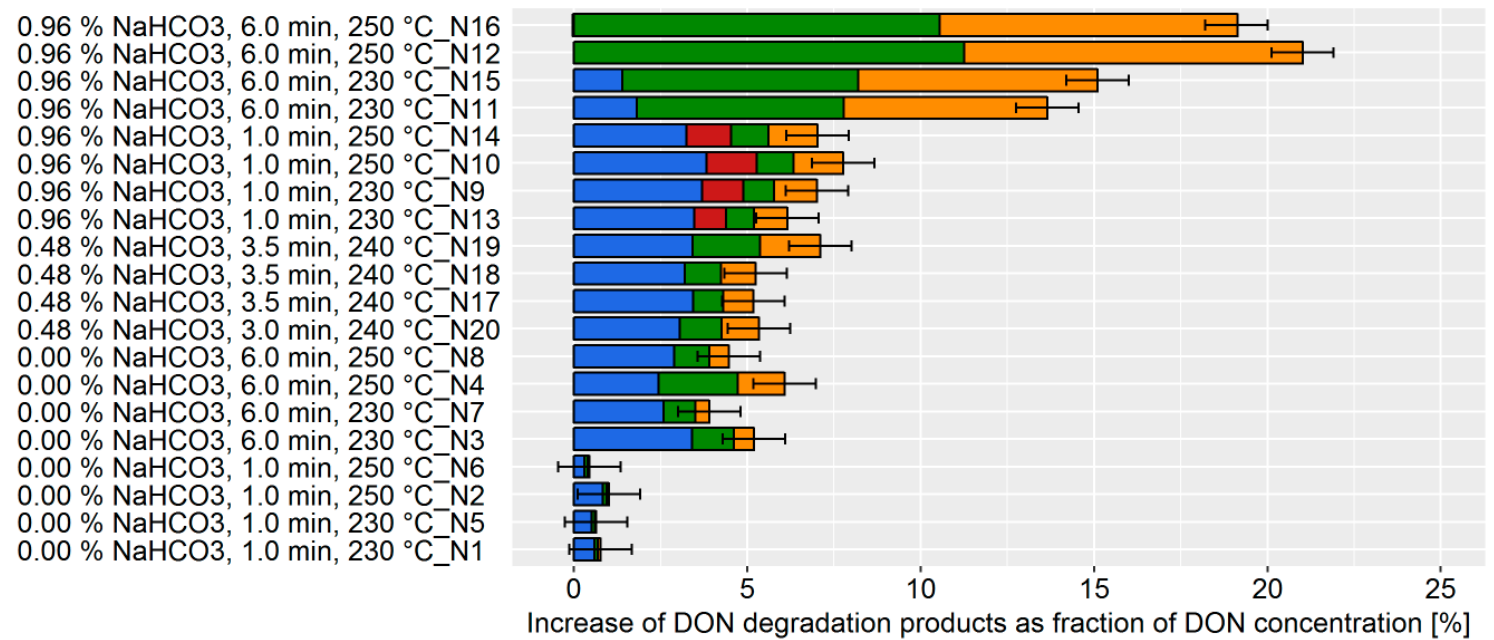

Compound $\square$ isoDON $\square$ norDON A $\square$ norDON B $\square$ norDON C

Figure 6. Increase of the deoxynivalenol (DON) degradation products isoDON and norDONs A-C during the production of crackers using different processing conditions. The increase was determined as a ratio of the molal concentration of the DON degradation products to the molal concentration of DON resulting from the natural contamination of the flour. The experimental trials were listed according to the $\mathrm{NaHCO}_{3}$ concentration, baking time, and baking temperature. Error bars represent the process standard deviation.

A high DON degradation was observed in experiments with a high $\mathrm{NaHCO}_{3}$ concentration, baking time, and baking temperature. Similar to the biscuit production, the variation of the processing parameter caused a change in the ratio of the degradation products. The DoE model revealed that $\mathrm{NaHCO}_{3}$ concentration and baking time were the main factors affecting DON degradation (Figure 7, top). In addition, the statistical model indicated that a synergistic effect of baking time and $\mathrm{NaHCO}_{3}$ concentration exists. The acidic mother concentration, leavening time, and baking temperature did not affect DON degradation. The prediction model revealed the potential DON reduction that can be achieved by process management (Figure 7, bottom). An increase of the $\mathrm{NaHCO}_{3}$ concentration from 0 to $1 \%$ is predicted to increase DON degradation by $10 \%$. Similarly, the increase of baking time from 1 to $6 \mathrm{~min}$ is predicted to increase DON degradation by $10 \%$. 

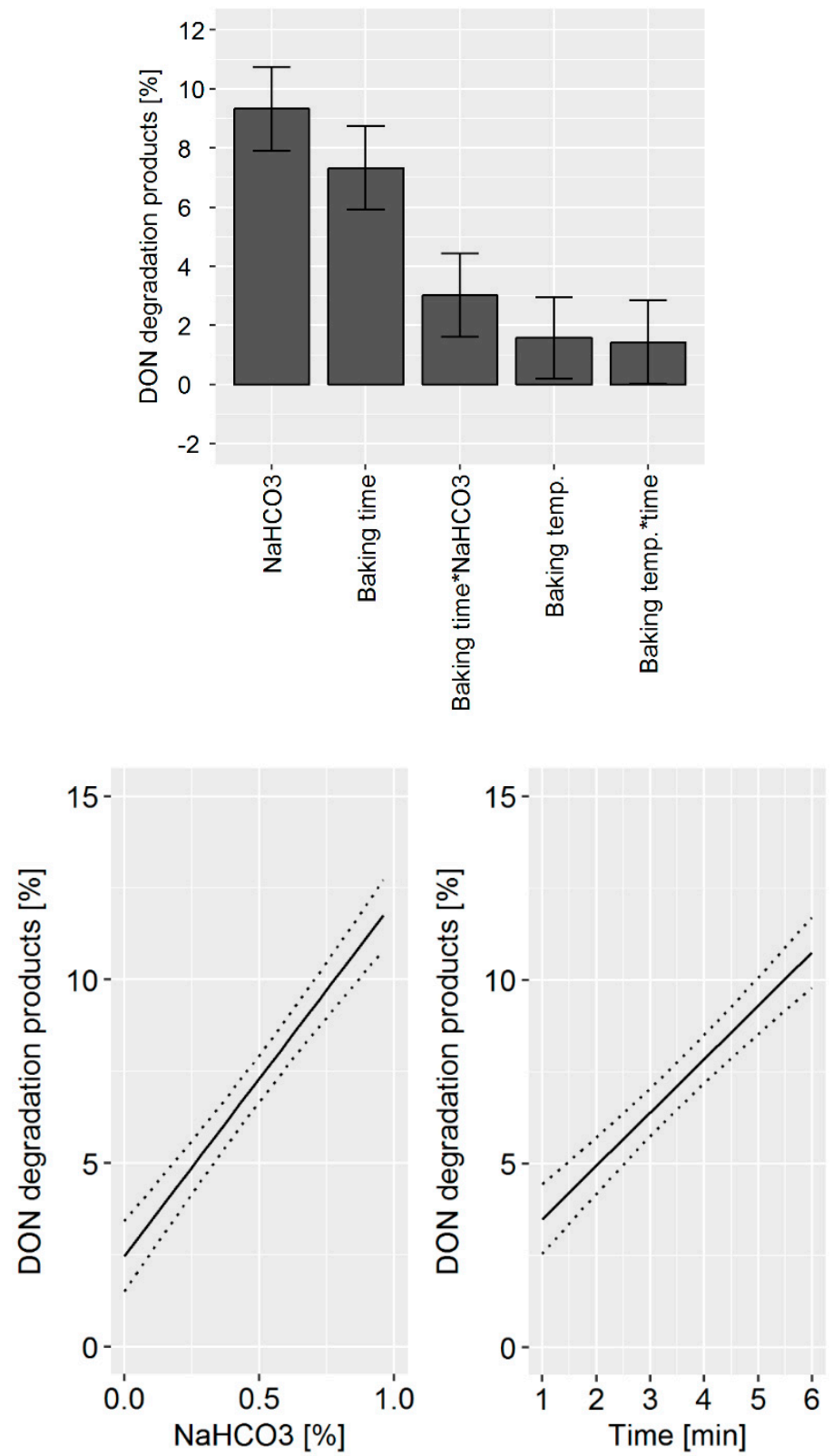

Figure 7. Top: Effects plot, which shows the change of the sum of the DON degradation products when a processing factor is varied from its lowest to its highest value and all other factors are kept at their averages, which was obtained for the design of the experiment (DoE) data set in pilot-scale bread making experiments. Error bars represent the confidence interval corresponding to a $95 \%$ confidence level. "** between two processing factors indicates a synergistic effect, which cannot be explained solely by addition of degradation caused by the two parameters individually. Bottom: Predictive factor effect plots, which show the influence of the following processing parameters on the deoxynivalenol (DON) degradation during the biscuit production: (i) $\mathrm{NaHCO} 3$ concentration (left) and (ii) baking time (right). The dotted lines represent the confidence interval corresponding to a 95\% confidence level.

\subsection{Cytotoxic Effects of isoDON}

The cytotoxic potential of isoDON in direct comparison to DON was evaluated in two different human colon cell lines (Figure 8). 

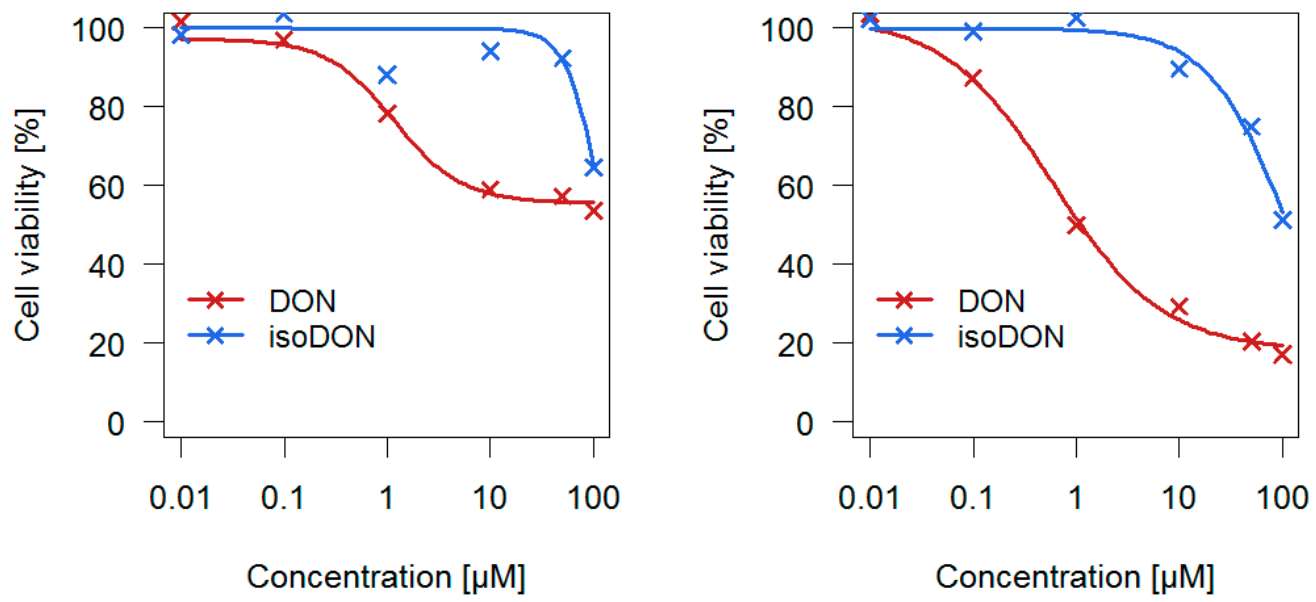

Figure 8. Cell viability of human colorectal adenocarcinoma cells (HT-29) (left) and non-tumorigenic human colon epithelial cells (HCEC) (right) after $24 \mathrm{~h}$ of incubation with different concentrations of deoxynivalenol (DON) and isoDON. The concentration at which cell viability was reduced by $30 \%$ $\left(\mathrm{IC}_{30}\right)$ was calculated from a dose response curve fitted to the individual data points $(\times)$.

Usually, the half maximal inhibitory concentration $\left(\mathrm{IC}_{50}\right)$ is used to compare the potency of two substances. As the highest tested isoDON concentrations did not reduce cell viability by $50 \%$ under all tested conditions, $\mathrm{IC}_{30}$ values where cell viability was reduced by $30 \%$ were used instead. For the human colorectal adenocarcinoma cell line HT-29 the following IC $_{30}$ values were determined: $1.9 \mu \mathrm{M}$ $(\mathrm{DON})$ and $91 \mu \mathrm{M}$ (isoDON), whereas for the non-tumorigenic human colon epithelial cells (HCEC) the following $\mathrm{IC}_{30}$ values were identified: $0.4 \mu \mathrm{M}$ (DON) and $53 \mu \mathrm{M}$ (isoDON). In both cell viability assays, isoDON was much less potent (factor 48 and 133 for HT-29 and HCEC, respectively) in reducing cellular viability compared to DON.

\section{Discussion}

\subsection{Influence of Different Processing Parameters on DON Degradation in Bakery Products}

\subsubsection{The $\mathrm{pH}$ Value of the Dough}

As DON has been reported to be unstable in alkaline solutions, the $\mathrm{pH}$ of the dough is clearly an important processing factor to consider when designing a production process that is optimized for a high DON degradation [13]. For the production of biscuits and crackers, the $\mathrm{pH}$ of the dough was regulated primarily by chemical raising agents. We found that the type of the chemical raising agent as well as its concentration was crucial regarding DON degradation. Whereas the use of $\mathrm{NaHCO}_{3}$ led to higher DON degradation, the use of $\mathrm{NH}_{4} \mathrm{HCO}_{3}$ did not influence DON concentration. This can be explained by the different $\mathrm{pH}$ values of the dough resulting from the different chemical nature of the raising agents. Gökmen et al. prepared cookies from two different doughs containing $0.7 \%$ $\mathrm{NaHCO}_{3}$ and $\mathrm{NH}_{4} \mathrm{HCO}_{3}$, respectively [14]. When $\mathrm{NaHCO}_{3}$ was used, the $\mathrm{pH}$ was initially 8.5 and increased slightly during baking to $\mathrm{pH}$ 9. In the absence of acidic compounds, $\mathrm{NaHCO}_{3}$ is thermally converted to $\mathrm{Na}_{2} \mathrm{CO}_{3}, \mathrm{H}_{2} \mathrm{O}$ and $\mathrm{CO}_{2}$ (Equation (1)). As $\mathrm{CO}_{3}{ }^{2-}$ is a stronger base than $\mathrm{HCO}_{3}{ }^{-}$, the thermal degradation of $\mathrm{NaHCO}_{3}$ leads to an increase of the ph. The use of $\mathrm{NH}_{4} \mathrm{HCO}_{3}$ as a leavening agent led to a decrease of the $\mathrm{pH}$ from 8 in the dough to 6-7 in the baked cookies. The decrease of $\mathrm{pH}$ can be explained by the degradation of $\mathrm{NH}_{4} \mathrm{HCO}_{3}$ to $\mathrm{NH}_{3}, \mathrm{CO}_{2}$ and $\mathrm{H}_{2} \mathrm{O}$, which evaporate during baking (Equation (2)).

$$
\begin{gathered}
2 \mathrm{NaHCO}_{3} \rightarrow \mathrm{Na}_{2} \mathrm{CO}_{3}+\mathrm{H}_{2} \mathrm{O}+\mathrm{CO}_{2} \\
\mathrm{NH}_{4} \mathrm{HCO}_{3} \rightarrow \mathrm{NH}_{3}+\mathrm{H}_{2} \mathrm{O}+\mathrm{CO}_{2}
\end{gathered}
$$


Besides chemical raising agents, further ingredients were shown to affect the $\mathrm{pH}$ of the dough. High $\mathrm{pH}$ values due to the presence of $\mathrm{NaHCO}_{3}$ were only observed when sucrose was used as sugar. At a higher $\mathrm{pH}$, sucrose was not hydrolyzed and thereby did not cause a change in $\mathrm{pH}$ [14]. When glucose was used, it was partially hydrolyzed to fructose resulting in a decrease of the $\mathrm{pH}$ from 8.5 in the dough to 6-7 in the baked cookies. This can be rationalized by the report of Feng et al. who calculated the $\mathrm{pKa}$ values for glucose and fructose [15]. Fructose was shown to be considerably more acidic $\left(\mathrm{pK}_{\mathrm{a}} 12\right)$ compared to glucose $\left(\mathrm{pK}_{\mathrm{a}} 14\right)$. In the presence of an acid, $\mathrm{NaHCO}_{3}$ was converted to $\mathrm{CO}_{2}$ which caused a decrease of the $\mathrm{pH}$ (Equation (3)).

$$
\mathrm{NaHCO}_{3}+\mathrm{H}^{+} \rightarrow \mathrm{Na}^{+}+\mathrm{H}_{2} \mathrm{O}+\mathrm{CO}_{2}
$$

For the biscuit production, our results confirm the outcome of a previous study, where the $\mathrm{NaHCO}_{3}$ concentration was the main factor that enhanced DON degradation [9]. For the cracker production, our results contradict a previous report in which baking temperature and time were found to be of higher importance compared to the $\mathrm{NaHCO}_{3}$ concentration. However, in the previous study, fewer experimental trials were carried out and the accuracy of the analytical methodology was lower.

\subsubsection{Baking Conditions}

For all three commodities, the baking conditions (i.e., temperature and/or time) influenced DON degradation. However, for the production of biscuits and crackers, baking conditions were less important compared to the $\mathrm{pH}$ of the dough. For the production of crackers and bread, baking time was found to be more important than baking temperature. The contrary was observed for biscuit production. The reason for this observation might relate to differences in moisture content and surface to volume ratio of the individual baking commodities.

\subsubsection{Ratio of the DON Degradation Products}

For the production of biscuits and crackers, the ratio of the DON degradation products shifted from isoDON to norDON B and $\mathrm{C}$ in the experiments that led to high DON degradation. This supports the proposed mechanism, that isoDON is further converted to norDON B and C [13]. Some baking conditions led to the formation of norDON A. Most likely, the reason why norDON A was not detected in a previous study was a higher limit of detection (LOD) and limit of quantification (LOQ) for norDON A compared to isoDON, norDON B and $C$ in the analytical method used [6]. Interestingly, the formation of norDON A was not observed in the experiments with the highest DON degradation (i.e., biscuits: N4, N16; crackers: N11, N12, N15, N16) in total. This might have been due to an initial formation of isoDON, which was further degraded into norDON A and finally to norDON B or norDON C.

\subsection{Toxicity of the DON Degradation Products}

For a comprehensive assessment of the health risks of eating bakery products produced from DON contaminated flour, the toxicity of all degradation products has to be determined. So far, norDONs A-C were shown to be considerably less cytotoxic than DON [5]. In comparison to DON, isoDON was found in in vitro translation assays to have a considerably lower potency (factor 94 and 60 in wheat and rabbit ribosomes, respectively) to inhibit translation, known to be the major mechanism of toxicity of trichothecenes [6]. As the $60 \mathrm{~S}$ subunit binding site of ribosomes is the main molecular target of DON, the results of the translation assay were indicative of considerably lower cytotoxicity $[16,17]$. However, various aspects, such as different cellular absorption, changes in distribution, and especially differences in fitting into the pockets of the ribosomal A-site due to changes in polarity might lead to significant differences in cytotoxicity of isoDON and DON. Therefore, the cytotoxic effects of isoDON in comparison to DON were evaluated. 


\section{Cytotoxic Effects of isoDON}

Performing cell viability assays in two different human colon cell lines, we found that isoDON induced significantly less cytotoxicity compared to DON in HCEC and HT-29 cells. In Figure 9, the structures of DON and isoDON, showing structural differences at the carbon atoms C-7 to C-10 of the trichothecene backbone, are displayed.

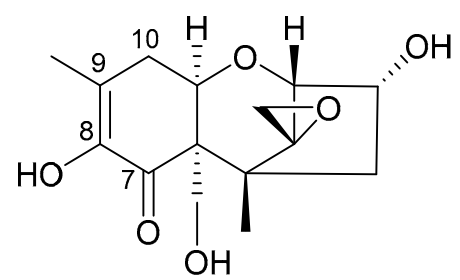

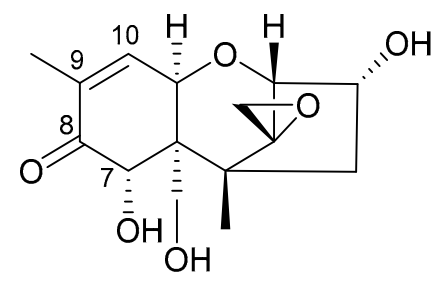

Figure 9. Structure of iso-deoxynivalenol (isoDON) (left) and DON (right). The C-7 to C-10 atoms of the trichothecene backbone are highlighted.

Our findings are supported by structure activity relationships which have been conducted for various trichothecenes [18-20]. The absence of a double bond at the C-9 and C-10 position, which is the case for isoDON, led to a significant decrease in both inhibition of protein biosynthesis and cytotoxicity. Although the toxicity of DON is often ascribed to the epoxide moiety, we could provide additional proof that a double bond between C-9 and C-10 is an essential structural feature for ribosomal inhibition and thus, for trichothecene-induced toxicity.

\section{Conclusions}

Depending on the processing conditions, $0-21 \%, 4-16 \%$, and $2-5 \%$ of DON were degraded during the production of crackers, biscuits, and bread, respectively. For biscuits and crackers, DON degradation can be increased by $10-20 \%$ by process management. For bread, process management can lead to a minor increase in DON degradation of about 3\%. DON degradation was enhanced by a high $\mathrm{NaHCO}_{3}$ concentration, baking time, and temperature. The processing parameters $\mathrm{NH}_{4} \mathrm{HCO}_{3}$, yeast, cider vinegar, acidic mother content, and sucrose concentration as well as leavening time did not influence DON concentration.

To put our findings in context to the results reported in recent literature, a graphical summary is presented in Figure 10.

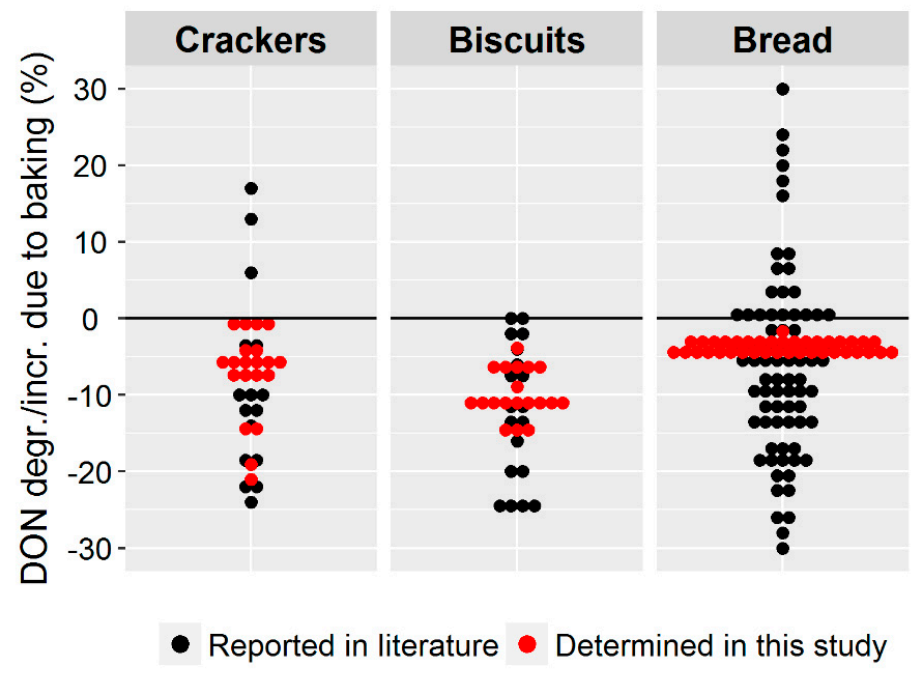

Figure 10. Comparison between the deoxynivalenol (DON) degradation reported in recent literature studies [10-12,21-29] and the DON degradation values determined in this study under different processing conditions. Each dot represents one baking experiment. 
Compared to previous studies found in the literature, we achieved a much narrower range of DON degradation, which was most pronounced for bread. The reason for that is most likely that we applied the currently most accurate analytical methodology to determine DON degradation [6].

To gain further knowledge about the toxicity of DON degradation products, the cytotoxicity of isoDON was evaluated by performing in vitro cell viability assays. isoDON was found to be considerably less cytotoxic (factor 48 and 133 for HT-29 and HCEC cells, respectively) compared to DON. As all DON degradation products are considerably less cytotoxic than DON, we conclude that DON degradation during baking results in a lower toxicity. Thus, for the first time, we have presented proof that baking under real industrial conditions can lead to a partial detoxification of DON.

\section{Materials and Methods}

\subsection{Chemicals and Reagents}

Acetonitrile (ACN, gradient grade) was purchased from VWR International GmbH (Vienna, Austria). Acetic acid (LC-MS gradient grade) was obtained from Sigma Aldrich (Vienna, Austria). In all experiments, ultra-pure water (purified by a Purelab Ultra system ELGA LabWater, Celle, Germany) was used. Liquid calibrant solutions of DOM-1, DON-3-Glc, DON, and U- $\left[{ }^{13} \mathrm{C}_{15}\right]$-DON were supplied by Romer Labs GmbH (Tulln, Austria). Reference standards of the DON degradation products isoDON and norDONs $\mathrm{A}, \mathrm{B}$ and $\mathrm{C}$ were synthesized according to published procedures $[5,6,21,30]$.

\subsection{Preparation of Bakery Products}

The food commodities used in the present study were produced from naturally contaminated flour according to the procedure previously described by our group by applying a suitable scaling up factor of the starting ingredients that fits with the production under pilot plant facilities [6].

Biscuits: The final dough ( $3000 \mathrm{~g}, 14 \%$ moisture content $(\mathrm{MC})$ ) was used to form the individual biscuits (approximately $11 \mathrm{~g}$ each) which consisted of $56 \mathrm{wt} \%$ flour, $40 \mathrm{wt} \%$ fat and sugar, and $4 \mathrm{wt} \%$ water.

Bread: The final dough ( $8000 \mathrm{~g}, 14 \% \mathrm{MC}$ ) was used to form the individual loafs of $450 \mathrm{~g}$ each $(40 \%$ $\mathrm{MC}$ ), that reached a final weight of $400 \mathrm{~g}$ and consisted of $65 \mathrm{wt} \%$ flour, yeast, oil, and salt and $35 \mathrm{wt} \%$ water after baking.

Crackers were shaped (approximately $10 \mathrm{~g}$ each) from the final dough ( $4127 \mathrm{~g}, 26 \% \mathrm{MC})$ and they consisted of $97 \mathrm{wt} \%$ flour, yeast, and malt extract and $3 \mathrm{wt} \%$ water.

\subsection{Design of Experiment (DoE) Setup and Statistical Evaluation}

Design of Experiments (DoE) was used to determine the influence of processing parameters on the degradation of DON and the increase of its degradation products during the baking of crackers, biscuits, and bread from naturally contaminated flour. The screening interaction model was chosen and processing parameters that we hypothesized to influence DON degradation were used as model quantitative factors. Table 1 provides a list of the processing parameters that were investigated in our study. For more detailed information on the processing parameters used in the individual experiments, the reader is referred to Tables S1, S4, and S7.

To focus the attention on the increase of DON degradation products during baking, multivariate data analysis was performed on the concentration $(\mu \mathrm{g} / \mathrm{kg})$ obtained by LC/MS-MS analysis in the finished products of the sum of DON degradation products. DoE set up and data elaboration were carried out by using MODDE software 11 (Umetrics, Umea, Sweden). 
Table 1. Processing parameters that were investigated for their impact on the degradation of deoxynivalenol during the production of bakery products from naturally contaminated flour under pilot plant conditions.

\begin{tabular}{cccc}
\hline Condition & Biscuits & Bread & Crackers \\
\hline Sucrose concentration [\%] & 12.5 to 17.5 & 0.41 to 1.41 & - \\
$\mathrm{NH}_{4} \mathrm{HCO}_{3}$ concentration [\%] & 0.21 to 0.61 & - & - \\
$\mathrm{NaHCO}_{3}$ concentration [\%] & 0.19 to 0.59 & - & 0.00 to 0.96 \\
Vinegar concentration [\%] & - & 0.00 to 0.36 & - \\
Yeast concentration [\%] & - & 0.83 to 1.33 & - \\
Leavening time [\%] & - & 70 to 100 & - \\
Acidity Mother [\%] & - & - & 0.65 to 1.65 \\
Baking time [min] & 7 to 11 & 15 to 29 & 1 to 6 \\
Baking temperature [ $\left.{ }^{\circ} \mathrm{C}\right]$ & 160 to 200 & 185 to 225 & 230 to 250 \\
\hline Total experiments & 19 & 38 & 20 \\
\hline
\end{tabular}

\subsection{Analysis of the Samples}

To determine DON degradation during the industrial baking process, the concentrations of DON and its degradation products (i.e., isoDON, norDON B, and norDON C) were analyzed in naturally contaminated flour and the products made thereof. Additionally, the concentration of the suspected DON degradation and conversion products DON-3-glucoside, DOM-1 and norDON A was monitored. Sample preparation and analysis are discussed in detail elsewhere [6]. In brief, $5.00 \pm 0.01 \mathrm{~g}$ of ground and homogenized sample was extracted with $20.0 \mathrm{~mL}$ of $\mathrm{ACN}: \mathrm{H}_{2} \mathrm{O}, 84: 16, v: v$. A total of $200 \mu \mathrm{L}$ of sample extract were dried down and reconstituted in $100 \mu \mathrm{L}$ of water. Subsequently, the concentrated sample extracts were centrifuged at $10^{\circ} \mathrm{C}$ and $4500 \mathrm{rpm}$ for $10 \mathrm{~min}$. Four $\mu \mathrm{L}$ aliquots of the concentrated sample extract were injected together with $0.4 \mu \mathrm{L}$ of internal standard into the HPLC system. Each sample was worked-up once and injected in duplicate. The analytical method used for the analysis was based on LC-MS/MS and was validated for recovery, repeatability, LOD, and LOQ. All results were corrected for the recovery factor determined in the validation study [6]. The concentration of the analytes that was found in naturally contaminated flour and in the finished bakery products can be found in Table S2 and S3 (biscuits), Table S5 and S6 (bread), and Table S8 and S9 (crackers) of the Supplementary Material, respectively.

\subsection{Calculation of the DON Degradation}

The sum of the DON degradation products was shown to be a much more accurate measure of the DON degradation than the change of the DON content itself [6]. Therefore, the DON degradation was calculated based on the increase of its degradation products isoDON and norDONs A-C. As the flour used for the production of the bakery products was naturally contaminated with the degradation products at different concentration levels, the increase of the degradation products was calculated separately before being summed up to obtain the final DON degradation.

\subsection{Calculation of the Increase of the DON Degradation Products Due to Baking}

For the production of bakery products from naturally contaminated flour, the increase of the degradation products was calculated according to:

$$
\begin{gathered}
\text { dilution factor }=\frac{m_{\text {flour }}}{m_{\text {bakery product }}} \\
b_{\text {analyte,dilution of nat.cont. flour }}=b_{\text {analyte, flour }} \text { dilution factor } \\
\text { Change due to baking }=\frac{b_{\text {analyte, bakery product }}-b_{\text {analyte, dilution of nat.cont. flour }}}{b_{D O N, \text { dilution of nat.cont. flour }}}
\end{gathered}
$$


First, the dilution factor, which describes the mass ratio of naturally contaminated flour present in the finished bakery product, was determined. The dilution factor was 0.97 (crackers), 0.56 (biscuits), and 0.65 (bread), respectively. Second, the theoretical molal concentration $b(\mathrm{~mol} / \mathrm{kg})$ of the analyte resulting from the dilution of the flour by the addition of other ingredients ( $b_{\text {analyte, dilution of nat.cont. flour }}$ ) was determined. Finally, the molal concentration of an analyte resulting from the natural contamination of the flour was subtracted from the molal concentration of the analyte in the bakery product ( $b_{\text {analyte, bakery product }}$ ) and expressed as a fraction of the molal concentration of DON resulting from the natural contamination of the flour. The result was the fraction of DON that is converted to DON degradation products during the production of bakery products.

\subsection{Estimation of the Process Standard Deviation}

In each DoE, three center points were set, which means that three experiments were carried out under identical processing conditions: Experiment number 17, 18 and 19 (crackers), 17, 18 and 19 (biscuits) and 33, 34, 35 (bread), respectively. The process standard deviation was calculated for the sum of the change of the degradation products of the three replicates which were produced using the same processing parameter. The process standard deviation was $0.9 \%, 1.4 \%$, and $0.8 \%$ for crackers, biscuits, and bread, respectively, and thus considerably higher than the analytical standard deviation for the determination of the sum of the DON degradation products which was in the range of $0.2-0.4 \%$ [6].

\subsection{Human Cell Culture}

Human colorectal adenocarcinoma cells, HT-29, were purchased from the German Collection of Microorganisms and Cell Cultures (DSMZ, Braunschweig, Germany). For cell culture Dulbecco's Modified Eagle's Medium (DMEM) supplemented with 10\% $(v / v)$ heat inactivated fetal calf serum and $50 \mathrm{U} / \mathrm{mL}$ penicillin and $50 \mu \mathrm{g} / \mathrm{mL}$ streptomycin was used. The non-tumorigenic human colon epithelial cell line, HCEC [31], was kindly provided by Prof. Jerry W. Shay (UT Southwestern Medical Center, Dallas, TX, USA). HCEC cells were cultivated in DMEM (high glucose) supplemented with $2 \%(v / v)$ Medium 199 (10×), 2\% (v/v) cosmic calf serum, $20 \mathrm{mM}$ 4-(2-hydroxyethyl)-1-piperazineethanesulfonic acid (HEPES), $50 \mu \mathrm{g} / \mathrm{mL}$ gentamicin, insulin-transferrin-selenium-G $(10 \mu \mathrm{g} / \mathrm{mL} ; 5.5 \mu \mathrm{g} / \mathrm{mL} ; 6.7 \mu \mathrm{g} / \mathrm{mL})$, recombinant human epidermal growth factor $(18.66 \mathrm{ng} / \mathrm{mL})$, and hydrocortisone $(1 \mu \mathrm{g} / \mathrm{mL})$. Both cell lines were cultivated in humidified incubators at $37^{\circ} \mathrm{C}$ and $5 \% \mathrm{CO}_{2}$. Media, supplements, and further material for cell culture were purchased from GIBCO Invitrogen (Karlsruhe, Germany), Lonza Group Ltd. (Basel, Switzerland), Sigma-Aldrich Chemie GmbH (Munich, Germany), Sarstedt AG \& Co. (Nuembrecht, Germany), and Fisher Scientific GmbH (Vienna, Austria).

\subsection{Cytotoxicity of isoDON}

Per well, 1500 HCEC or 5500 HT-29 cells were seeded in a $200 \mu \mathrm{L}$ culture medium in 96-well plates and allowed to grow for $48 \mathrm{~h}$. Then, the culture medium was withdrawn and cells were treated with different concentrations of isoDON and DON in the respective cell culture medium for $24 \mathrm{~h}$. As a solvent control, $1 \%$ water (LC-MS grade) was incubated and $1 \%(v / v)$ Triton X-100 served as a positive control. After the treatment period, the medium was withdrawn and cells were rinsed once with phosphate buffered saline $(100 \mu \mathrm{L} /$ well $)$ and incubated with DMEM containing $10 \%(v / v)$ alamarBlue ${ }^{\circledR}$ reagent (Invitrogen ${ }^{\mathrm{TM}}$ Life Technologies, Karlsruhe, Germany) for $75 \mathrm{~min}$. Subsequently, fluorescence intensity was measured (excitation: $530 \mathrm{~nm}$; emission: $600 \mathrm{~nm}$ ) on a Cytation 3 Imaging Multi Mode Reader (BioTek, Bad Friedrichshall, Germany). For quantification, blank-values were subtracted and measured data were referred to solvent control. Data are presented as a mean of at least five independent experiments, each performed in technical triplicates.

Supplementary Materials: The following are available online at http://www.mdpi.com/2072-6651/11/6/317/s1, Table S1: Processing parameters used for the production of biscuits in different experiments (Exp. No.). Ingredients are given as the weight percentage of the dough; Table S2: Concentration of the analytes in the naturally contaminated flour, dilution factor by which the flour gets diluted in the final biscuits, and the resulting 
concentration (assuming $0 \%$ degradation). <LOQ: concentration was below the limit of quantification (LOQ) of the analytical methodology. Table S3: Concentration of deoxynivalenol (DON) and related compounds in the biscuit samples. <LOQ: concentration was below the limit of quantification (LOQ) of the analytical methodology; Table S4: Processing parameters used for the production of bread in different experiments (Exp. No.). Ingredients are given as the weight percentage of the dough; Table S5: Concentration of the analytes in the naturally contaminated flour, dilution factor by which the flour gets diluted in the final bread, and the resulting concentration (assuming $0 \%$ degradation). n.d. (not detected): Concentration was below the limit of quantification of the analytical methodology; Table S6: Concentration of deoxynivalenol (DON) and related compounds in bread samples. n.d. (not detected): Concentration was below the limit of quantification of the analytical methodology; Table S7: Processing parameters used for the production of crackers in different experiments (Exp. No.). Ingredients are given as the weight percentage of the dough; Table S8: Concentration of the analytes in the naturally contaminated flour, dilution factor by which the flour gets diluted in the final crackers, and the resulting concentration (assuming $0 \%$ degradation). n.d. (not detected): Concentration was below the limit of quantification of the analytical methodology; Table S9: Concentration of deoxynivalenol (DON) and related compounds in cracker samples. n.d. (not detected): Concentration was below the limit of quantification of the analytical methodology.

Author Contributions: Conceptualization, D.S., F.L., M.S., F.B. and R.K.; methodology, D.M., M.S. and R.K.; data curation, D.S., F.L. and L.W.; toxicity study, L.W and D.M.; visualization, D.S. and F.L.; writing-original draft preparation, D.S., F.L. and L.W.; writing—review and editing, all authors; supervision, D.M., M.S., F.B. and R.K.; project administration and funding acquisition, D.M., M.S. and R.K.

Funding: This project has received funding from the European Union's Horizon 2020 research and innovation programme under grant agreement No. 678012 for the MyToolBox project, also covering the APC. We also acknowledge financial support from the Austrian Science Fund (FWF) via the special research project Fusarium (F3718).

Acknowledgments: The authors would like to thank the colleagues for the pilot plant trials execution support: Dante Catellani, Marta Filomeno, Gennaro Cangiano, Sergio Cerasti and Umberto Tanzi.

Conflicts of Interest: The authors declare no conflict of interest. The funders had no role in the design of the study; in the collection, analyses, or interpretation of data; in the writing of the manuscript, or in the decision to publish the results.

\section{References}

1. Pitt, J.I.; Wild, C.P.; Baan, R.A.; Gelderblom, W.C.A.; Miller, J.D.; Riley, R.T.; Wu, F. Improving Public Health through Mycotoxin Control; IARC Scientific Publications Series, No. 158; International Agency for Research on Cancer: Lyon, France, 2012.

2. Knutsen, H.K.; Alexander, J.; Barregård, L.; Bignami, M.; Brüschweiler, B.; Ceccatelli, S.; Cottrill, B.; Dinovi, M.; Grasl-Kraupp, B.; Hogstrand, C.; et al. Risks to human and animal health related to the presence of deoxynivalenol and its acetylated and modified forms in food and feed. EFSA J. 2017, 15. [CrossRef]

3. European Commission. European Commission Commission Regulation (EC) No 1881/2006 of 19 December 2006 setting maximum levels for certain contaminants in foodstuff. Off. J. Eur. Union 2006, 364, 5-24.

4. Greenhalgh, R.; Gilbert, J.; King, R.R.; Blackwell, B.A.; Startin, J.R.; Shepherd, M.J. Synthesis, characterization, and occurrence in bread and cereal products of an isomer of 4-deoxynivalenol (vomitoxin). J. Agric. Food Chem. 1984, 32, 1416-1420. [CrossRef]

5. Bretz, M.; Beyer, M.; Cramer, B.; Knecht, A.; Humpf, H.U. Thermal degradation of the Fusarium mycotoxin deoxynivalenol. J. Agric. Food Chem. 2006, 54, 6445-6451. [CrossRef] [PubMed]

6. Stadler, D.; Lambertini, F.; Bueschl, C.; Wiesenberger, G.; Hametner, C.; Schwartz-zimmermann, H.; Hellinger, R.; Sulyok, M.; Lemmens, M.; Schuhmacher, R.; et al. Untargeted LC-MS based 13C labelling provides a full mass balance of deoxynivalenol and its degradation products formed during baking of crackers, biscuits and bread. Food Chem. 2019, 279, 303-311. [CrossRef] [PubMed]

7. Schaarschmidt, S.; Fauhl-Hassek, C. The fate of mycotoxins during the processing of wheat for human consumption. Compr. Rev. Food Sci. Food Saf. 2018, 17, 556-593. [CrossRef]

8. Khaneghah, M.A.; Fakhri, Y.; Sant'Ana, A.S. Impact of unit operations during processing of cereal-based products on the levels of deoxynivalenol, total a $\mathrm{fl}$ atoxin, ochratoxin A, and zearalenone: A systematic review and meta-analysis. Food Chem. 2018, 268, 611-624. [CrossRef] [PubMed]

9. Generotti, S.; Cirlini, M.; Šarkanj, B.; Sulyok, M.; Berthiller, F.; Dall'Asta, C.; Suman, M. Formulation and processing factors affecting trichothecene mycotoxins within industrial biscuit-making. Food Chem. 2017, 229, 597-603. [CrossRef] [PubMed] 
10. Suman, M.; Manzitti, A.; Catellani, D. A design of experiments approach to studying deoxynivalenol and deoxynivalenol-3-glucoside evolution throughout industrial production of wholegrain crackers exploiting LC-MS/MS techniques. World Mycotoxin J. 2012, 5, 241-249. [CrossRef]

11. Generotti, S.; Cirlini, M.; Malachova, A.; Sulyok, M.; Berthiller, F.; Dall'Asta, C.; Suman, M. Deoxynivalenol \& deoxynivalenol-3-glucoside mitigation through bakery production strategies: Effective experimental design within industrial rusk-making technology. Toxins 2015, 7, 2773-2790. [PubMed]

12. Bergamini, E.; Catellani, D.; Dall'Asta, C.; Galaverna, G.; Dossena, A.; Marchelli, R.; Suman, M. Fate of fusarium mycotoxins in the cereal product supply chain: The deoxynivalenol (DON) case within industrial bread-making technology. Food Addit. Contam. 2010, 27, 677-687. [CrossRef] [PubMed]

13. Young, J.C.; Blackwell, B.A.; ApSimon, J.W. Alkaline degradation of the mycotoxin 4-deoxynivalenol. Tetrahedron Lett. 1986, 27, 1019-1022. [CrossRef]

14. Gökmen, V.; Açar, Ö.Ç.; Serpen, A.; Morales, F.J. Effect of leavening agents and sugars on the formation of hydroxymethylfurfural in cookies during baking. Eur. Food Res. Technol. 2008, 226, 1031-1037. [CrossRef]

15. Feng, S.; Bagia, C.; Mpourmpakis, G. Determination of proton affinities and acidity constants of sugars. J. Phys. Chem. A 2013, 117, 5211-5219. [CrossRef] [PubMed]

16. Cundliffe, E.; Cannon, M.; Davies, J. Mechanism of inhibition of eukaryotic protein synthesis by trichothecene fungal toxins. Proc. Natl. Acad. Sci. USA 1974, 71, 30-34. [CrossRef] [PubMed]

17. Ueno, Y.; Nakajima, M.; Sakai, K.; Ishii, K.; Sato, N. Comparative toxicology of trichothec mycotoxins: Inhibition of protein synthesis in animal cells. J. Biochem. 1973, 74, 285-296.

18. Anderson, D.W.; Black, R.M.; Lee, C.G.; Pottage, C.; Rickard, R.L.; Sandford, M.S.; Webber, T.D.; Williams, N.E. Structure-Activity Studies of Trichothecenes: Cytotoxicity of Analogues and Reaction Products Derived from T-2 Toxin and Neosolaniol. J. Med. Chem. 1989, 32, 555-562. [CrossRef]

19. Wu, Q.; Dohnal, V.; Kuca, K.; Yuan, Z. Trichothecenes: Structure-toxic activity relationships. Curr. Drug Metab. 2013, 14, 641-660. [CrossRef] [PubMed]

20. Wei, C.; Mclaughlin, S. Structure-function relationship in the 12,13-epoxytrichothecenes. Biochem. Biophys. Commun. 1974, 57, 838-844. [CrossRef]

21. Scudamore, K.A.; Hazel, C.M.; Patel, S.; Scriven, F. Deoxynivalenol and other Fusarium mycotoxins in bread, cake, and biscuits produced from uk-grown wheat under commercial and pilot scale conditions. Food Addit. Contam. 2009, 26, 1191-1198. [CrossRef]

22. Voss, K.A.; Snook, M.E. Stability of the mycotoxin deoxynivalenol (DON) during the production of flour-based foods and wheat flake cereal. Food Addit. Contam. 2010, 27, 1694-1700. [CrossRef] [PubMed]

23. Vidal, A.; Sanchis, V.; Ramos, A.J.; Marín, S. Thermal stability and kinetics of degradation of deoxynivalenol, deoxynivalenol conjugates and ochratoxin A during baking of wheat bakery products. Food Chem. 2015, 178, 276-286. [CrossRef] [PubMed]

24. De Angelis, E.; Monaci, L.; Pascale, M.; Visconti, A. Fate of deoxynivalenol, T-2 and HT-2 toxins and their glucoside conjugates from flour to bread: An investigation by high-performance liquid chromatography high-resolution mass spectrometry. Food Addit. Contam. Part A 2013, 30, 345-355. [CrossRef] [PubMed]

25. Kostelanska, M.; Dzuman, Z.; Malachova, A.; Capouchova, I.; Prokinova, E.; Skerikova, A.; Hajslova, J. Effects of milling and baking technologies on levels of deoxynivalenol and its masked form deoxynivalenol-3-glucoside. J. Agric. Food Chem. 2011, 59, 9303-9312. [CrossRef] [PubMed]

26. Lancova, K.; Hajslova, J.; Kostelanska, M.; Kohoutkova, J.; Nedelnik, J.; Moravcova, H.; Vanova, M. Fate of trichothecene mycotoxins during the processing: Milling and baking. Food Addit. Contam. Part A 2008, 25, 650-659. [CrossRef] [PubMed]

27. Valle-Algarra, F.M.; Mateo, E.M.; Medina, Á.; Mateo, F.; Gimeno-Adelantado, J.V.; Jiménez, M. Changes in ochratoxin A and type B trichothecenes contained in wheat flour during dough fermentation and bread-baking. Food Addit. Contam. Part A Chem. Anal. Control. Expo. Risk Assess. 2009, 26, 896-906. [CrossRef] [PubMed]

28. Vidal, A.; Morales, H.; Sanchis, V.; Ramos, A.J.; Marín, S. Stability of DON and OTA during the breadmaking process and determination of process and performance criteria. Food Control. 2014, 40, 234-242. [CrossRef]

29. Wu, L.; Wang, B. Evaluation on levels and conversion profiles of DON, 3-ADON, and 15-ADON during bread making process. Food Chem. 2015, 185, 509-516. [CrossRef] 
30. Schwartz-Zimmermann, H.E.; Hametner, C.; Nagl, V.; Fiby, I.; Macheiner, L.; Winkler, J.; Dänicke, S.; Clark, E.; Pestka, J.J.; Berthiller, F. Glucuronidation of deoxynivalenol (DON) by different animal species: Identification of iso-DON glucuronides and iso-deepoxy-DON glucuronides as novel DON metabolites in pigs, rats, mice, and cows. Arch. Toxicol. 2017, 91, 3857-3872. [CrossRef]

31. Roig, A.I.; Eskiocak, U.; Hight, S.K.; Kim, S.B.U.M.; Delgado, O.; Souza, R.F.; Spechler, S.J.; Wright, W.E.; Shay, J.W. Immortalized epithelial cells derived from human colon biopsies express stem cell markers and differentiate in vitro. Gastroenterology 2010, 138, 1012-1021. [CrossRef]

(C) 2019 by the authors. Licensee MDPI, Basel, Switzerland. This article is an open access article distributed under the terms and conditions of the Creative Commons Attribution (CC BY) license (http://creativecommons.org/licenses/by/4.0/). 